\title{
Nutritional improvement of metabolic syndrome parameters in immature fructose-fed wild-type mice
}

\author{
J.C. CHA, V. IVANOV, M.W. ROOMI, T. KALINOVSKY, A. NIEDZWIECKI and M. RATH \\ Dr Rath Research Institute, Santa Clara, CA 95050, USA
}

Received May 12, 2011; Accepted August 11, 2011

DOI: $10.3892 / \mathrm{mmr} .2011 .562$

\begin{abstract}
The incidence of type 2 diabetes mellitus is on the increase worldwide, with both environmental and genetic factors implicated in its development. Diabetes is often preceded by metabolic syndrome (MS) and may develop in normal adults ingesting a high fructose diet. The effect of high fructose intake on the development of MS in children and adolescents is less clear. Our objective was to study the effects of a nutrient mixture and metformin (MET), a widely used oral diabetic medication, in modulating the physiological and biochemical parameters of a high fructose diet in immature mice. C57BL/6J wild-type mice aged 7 weeks were administered $12 \%$ fructose in their water and MET in distilled water or a diabetic nutrient mix (DNM) over 7 weeks. DNM-fed mice showed a decrease in systolic blood pressure, total cholesterol and fructosamine compared to the fructose-fed only group $(\mathrm{p}<0.05)$. A discordant result was observed in the MET group, with a decrease in blood pressure but increases in total cholesterol and fructosamine $(\mathrm{p}<0.05)$. Serum glucose did not change significantly among the groups. Thus, symptoms of fructose-induced MS in young mice could be countered nutritionally. Additionally, MET may improve certain biochemical markers while worsening others.
\end{abstract}

\section{Introduction}

The incidence of type 2 diabetes continues to increase worldwide, despite increased understanding of its pathogenesis and novel drug therapies $(1,2)$. An increased intake of fructose and sucrose in Western nations over the past six decades is implicated in the diabetes mellitus epidemic, with heritable genetic predisposition also playing a role. Diabetes may be preceded by metabolic syndrome (MS), a constellation of symptoms that include obesity, hypertension, impaired glucose tolerance, hyperinsulinemia, hypertriglyceridemia and hypercholesterolemia. High fructose diets have been shown to induce MS

Correspondence to: Dr Aleksandra Niedzwiecki, Dr Rath Research Institute, 1260 Memorex Drive, Santa Clara, CA 95050, USA E-mail: author@drrath.com

Key words: diabetes nutrient mix, metformin, C57/BL6 J wild-type mice, fructose diet, metabolic syndrome parameters, fructosamine, lipid profile, systolic blood pressure in adult men (3), and animals fed a diet high in fructose had an increase in nocturnal hypertension and autonomic instability (4). Chronic MS may eventually lead to fasting hyperglycemia and diabetes mellitus, or type 2 diabetes.

Hyperglycemia may cause non-enzymatic glycation of lipids and proteins, leading to the production of advanced glycation end products (AGE), which denature functional proteins. By direct binding to proteins following spontaneous rearrangement and autoxidation, excess blood sugar generates ketoamines (fructosamine), and 200-50,000-fold more reactive carbonyls, including glyoxal, methylglyoxal and 3-deoxyglucosone (5). Of these, methylglyoxal (MGO) is a well-characterized causative agent of diabetic organ damage. MGO leads to oxidative stress of tissues, and affects vascular endothelial cells, as well as pancreatic islet cells, resulting in dyslipidemia, renal insufficiency and, ultimately, insulin resistance (6). The serum fructosamine level is used clinically as an accurate marker of recent glycemic control, as well as an indicator of recent protein glycation $(7,8)$. In respect to MS and type 2 diabetes, elevated fructosamine and MGO present additional therapeutic targets. Patients who do not treat or lower their chronic hyperglycemia eventually suffer from one or a combination of atherosclerosis, cardiomyopathy, nephropathy, neuropathy, retinopathy, failure of wound healing and immune system dysfunction. Untreated type 2 diabetes is associated with an all-cause mortality rate of at least $50 \%$ upon diagnosis (9).

Current therapies, including metformin (MET) or rosiglitazone, modulate metabolic pathways such as AMPK (10) or PPAR- $\gamma$ (11), respectively, but do not address the cause of diabetes mellitus. Additionally, the toxicities of these drugs include increased incidences of cardiovascular pathologies (11), as well as other unknown long-term effects, including enhanced $\beta$-amyloid production (12). Effective therapies with an improved safety profile are an unmet medical need. Numerous compounds show positive effects in the control of diabetic parameters.

Nutritional modification of diabetes mellitus has been the subject of intense study by a number of laboratories worldwide, as numerous nutritional therapeutics offer the advantage of unparalleled safety as well as reduced cost. For example, arginine and other amino acids were shown to synergize insulin secretion and insulin sensitivity (13) and the protein extract was found to exert a hypoglycemic effect (14). B-vitamins, such as thiamine, have improved complications of diabetes mellitus $(15,16)$. Ascorbic acid has long been used as an aldose reductase 
inhibitor, improving the outcome of chronic hyperglycemia (17). Additionally, ascorbic acid affords a neuroprotective benefit in diabetic rats (18). Polyphenols have been shown to improve glucose metabolism, independently of insulin, as well as to aid in the prevention of protein glycation, a factor in hemoglobin damage $(19,20)$. Components in cinnamon extract (catechin, epicatechin, procyanidin B2 and phenol polymers) are known to block AGE products, minimizing the deleterious effects by these intermediaries on the vasculature (21). Numerous other dietary products have been shown to reduce hyperglycemia and insulin resistance (22-24), and modify cardiovascular risk factors in diabetes (25).

The role of a high fructose diet in the development of childhood and adolescent MS is largely unknown. Towards this aim, this study examined the physiological and metabolic effects of dietary-induced metabolic changes caused by a high carbohydrate diet in young adolescent wild-type C57BL/6J mice treated with oral administration of MET or the diabetic nutrient mixture (DNM), containing grape seed extract, cinnamon, $\alpha$ lipoic acid, arginine, lysine, thiamine, pyridoxine and ascorbic acid. Each of the components has a specific biochemical mechanism by which it may improve diabetes mellitus. Wild-type rodents, fed excessive sucrose or fructose, have been shown to develop MS (26).

\section{Materials and methods}

Animals. Male wild-type C57BL/6J mice ( $\mathrm{n}=24)$, approximately 6 weeks of age, were purchased from Jackson Laboratories (Bar Harbor, ME, USA) and acclimated for a week prior to treatment. Animals were housed in standard separator cages with bedding on a 24-h light/dark schedule. All animals were cared for in accordance with institutional guidelines for the care and use of experimental animals.

Diet. The regular diet was the laboratory rodent diet 5001 from Purina Mills (Gray Summit, MO, USA), LLC/test diet. The $1.5 \%$ diabetes nutrient mix diet was milled and pressed by Purina Mills, LLC and generated by Vitatech (Tustin, CA, USA). The DNM diet consisted of the following: $8.35 \%$ ActiVin ${ }^{\circledR}$ grape seed extract (San Joaquin Valley Concentrates, Fresno, CA, USA), 8.35\% CinSulin ${ }^{\circledR}$ water extract comprising cinnamon, $8.35 \%$ green tea extract, $2.41 \% \alpha$ lipoic acid, $21.11 \%$ L-arginine $\mathrm{HCl}, 12.20 \%$ L-lysine $\mathrm{HCl}, 20.28 \%$ thiamine $\mathrm{HCl}$, $2.40 \%$ pyridoxine $\mathrm{HCl}, 2.94 \%$ ascorbic acid, $3.56 \%$ calcium ascorbate, $3.13 \%$ magnesium ascorbate and $6.92 \%$ ascorbyl palmitate. This mixture was formulated based on the reported benefits of each individual component from the literature and the ability of each to chelate methylglyoxal (MGO). Fig. 1 shows the results of screening of MGO chelation by the components.

Screening of MGO chelation: HPLC. For the screening of MGO chelation, an HPLC assay developed by Peng et al (21) for cinnamon polyphenol sequestration of MGO was adapted. The compound or compound mixtures were incubated directly with MGO at a stoichiometric ratio, the carbonyl responsible for AGE formation in vivo, to observe whether the nutrients bind MGO. Nutrient sequestering/trapping of MGO prevents MGO from being derivatized by 1, 2-phenylenediamine (PD) to 1-methylquinoxaline (MQ). The greater the trapping activity of the nutrient mixture, the less derivatized the presence of MQ. A total amount of $5 \mathrm{mM}$ MGO, $20 \mathrm{mM}$ 1,2-PD (derivatization reagent) and $5 \mathrm{mM}$ 2,3-dimethylquinoxaline (DQ) (internal standard) were separately prepared in phosphate-buffered saline (PBS), 50/50\%, PBS/methanol, respectively. A total amount of $0.25 \mathrm{ml}$ of the MGO solution was mixed with $0.5 \mathrm{ml}$ of PBS blank or $0.25 \mathrm{ml}$ of the $5 \mathrm{mM}$ the lowest dose range nutrient mix and $0.25 \mathrm{ml}$ PBS for a total incubation volume of $0.75 \mathrm{ml}$. The mixture was incubated at $37^{\circ} \mathrm{C}$ in a water bath for $1 \mathrm{~h}$, followed by the addition of $0.125 \mathrm{ml}$ of $20 \mathrm{mM}$ PD. The mixture was vortexed for $5 \mathrm{sec}$ and incubated for $30 \mathrm{~min}$ at $37^{\circ} \mathrm{C}$ to allow derivatization of MGO to 1-MQ. A total amount of $0.125 \mathrm{mM}$ of internal standard DQ was added last as it is dissolved in 50\% methanol, 50\% PBS and the methanol may interfere with the derivatization. After $30 \mathrm{~min}$, the mixture was run on a Shimadzu HPLC with $15 \mu$ l injection, isocratic $1.0 \mathrm{ml} / \mathrm{min}$ flow, $315 \mathrm{~nm}$ UV detection, and running for $10 \mathrm{~min} /$ sample. The mobile phase was 50:50 water:methanol, and the column used was a Luna Phenyl-Hexyl column (150x4.6 mm, $5 \mu \mathrm{M}$, Phenomenex, Torrance, CA, USA). The ratio of MQ/DQ was used to detect the amount of unreacted (trapped) MGO. The decrease percentage in MGO was calculated using the formula: [(amounts of MGO (MQ) in the control - amounts of MGO (MQ) in the sample with tested fraction or compound)/ amounts of MGO (MQ) in the control] x $100 \%$.

Experimental design. At 7 weeks of age, mice were separated into 4 groups of 6 mice each and treated for 7 additional weeks prior to evaluation. Mice in group A received distilled water with $12 \%$ fructose and were fed a regular diet. Group B mice received distilled water with $12 \%$ fructose and $300-500 \mathrm{mg} /$ $\mathrm{kg} /$ day of MET (Sigma), and were fed the regular diet. Group C received distilled water with $12 \%$ fructose and was fed the $1.5 \%$ DNM-supplemented diet. Group D was maintained on normal food and water for the 7 weeks. At 6 weeks, mice were acclimated to systolic blood pressure testing with no other changes. Mice were weighed under brief isofluorane anesthesia on a standard laboratory Mettler scale prior to non-fasted urine collection and end-stage serum collection. Paraffin wrap was previously laid down on a table, and tubes were prepared for urine storage. To collect urine, awake mice were grasped around the nape of the neck with thumb and forefingers and immobilized while suspended over the paraffin wrap. The volume of spontaneously voided urine was recorded and the urine stored at $-80^{\circ} \mathrm{C}$ until it was assayed. To obtain serum, mice were anaesthetized under isofluorane, and as much blood was drawn as possible through left ventricular puncture. All procedures were conducted under protocols approved by the Internal Animal Care and Use Committee (IACUC).

Measurement of systolic blood pressure. Blood pressure was obtained through the tail cuff method using the CODA system (Kent Scientific, Inc., Torrington, CT, USA). Measurements were made in the afternoon to ensure consistent diurnal blood pressure recordings between the groups. A week prior to experimental measurements, mice were acclimated to the procedure twice, separated by 2 days. Mice were placed in a fitted retainer unit, and maintained on a warming bench at $37^{\circ} \mathrm{C}$ under shade. Up to 100 cycles of $30 \mathrm{sec}$ measurements 


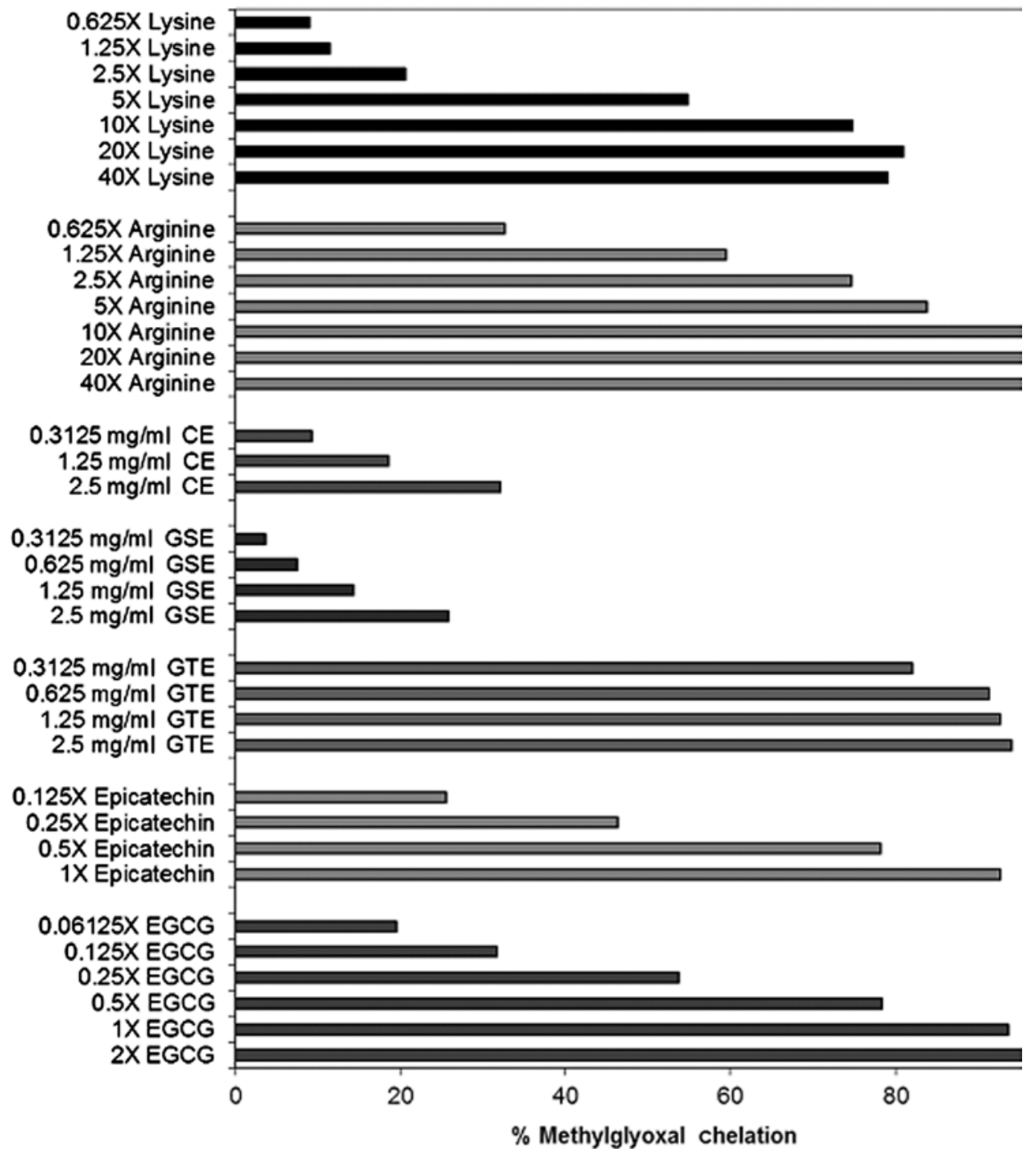

Figure 1. Stoichiometric chelation of $5 \mathrm{mM}$ methylglyoxal (MGO) by components of the diabetes nutrient mix. CE, cinnamon extract; GSE, grape seed extract; GTE, green tea extract; EGCG, epigallocatechin gallate.

were obtained with 10 initial acclimation cycles. After readings stopped fluctuating significantly, the average of at least three consecutive measurements was recorded per mouse.

Serum analyses. Plasma was allowed to sit upright in Eppendorf tubes for $30 \mathrm{~min}$ at room temperature. Coagulated edges were rimmed down and tubes were centrifuged at 2,500 rpm for $20 \mathrm{~min}$. Serum was placed in fresh tubes and stored at $-8^{\circ} \mathrm{C}$ until it was assayed. Portions of sera were shipped frozen and tested for the lipid panel and fructosamine analyses at IDEXX Laboratories (Westbrook, ME, USA). The remaining sera were tested for glucose (Glucose Assay kit; BioVision, Mountain View, CA, USA) and insulin (Ultra Sensitive Mouse Insulin ELISA kit; Crystal Chem Inc., Downers Grove, IL, USA). The low range standard curve $(0-6.4 \mathrm{ng} / \mathrm{ml})$ of the insulin kit was used.

Urine analyses. Total protein in urine was measured in urine diluted at 1:10 using the BCA Protein Assay kit (Pierce, Rockford, IL, USA). Creatinine concentration was obtained with the Arbor Assays Creatinine kit according to the manufacturer's instructions. Glucose concentrations in undiluted urine were obtained using the Biovision Glucose kit. Urinary glucose and creatinine concentrations between groups were assessed per equal volume or normalized to total protein concentration per equal volume.

Data analysis. Statistical procedures were carried out using MedCalc (Mariakerke, Belgium) and Microsoft Excel. One-way ANOVA analysis was conducted between the groups using the means and standard deviations, as well as an independent samples t-test between the groups. Values are expressed as the mean \pm SD or percentage changes of control values. $\mathrm{P} \leq 0.05$ was considered to be statistically significant.

\section{Results}

The biochemical and physiological data are shown in Tables I and II.

Serum concentration of fructosamine. Data were obtained from 23 mice $(n=5$ for the fructose-fed group, $n=6$ for the remaining groups). The levels of fructosamine at the end of 7 weeks were measured for all of the cohorts. Both the positive-control MET arm and the fructose-only arm exhibited a 
Table I. Comparative effects of diets and treatments on physiological parameters and serum levels.

\begin{tabular}{|c|c|c|c|c|c|}
\hline $\begin{array}{l}\text { Serum/physiological } \\
\text { parameters }\end{array}$ & Units & $\begin{array}{l}\text { Fructose }(12 \%) \\
\text { and normal diet } \\
\qquad(n=5)\end{array}$ & $\begin{array}{c}\text { Fructose }(12 \%) \\
\text { and MET }(2 \mathrm{mg} / \mathrm{ml}) \\
\text { and normal diet } \\
\qquad(\mathrm{n}=6)\end{array}$ & $\begin{array}{l}\text { Fructose }(12 \%) \\
\text { and DNM } \\
\qquad(n=6)\end{array}$ & Normal diet \\
\hline Fructosamine & $\mu \mathrm{mol} / 1$ & $365.80 \pm 42.82$ & $392.67 \pm 40.69$ & $325.50 \pm 21.60$ & $338.83 \pm 29.01$ \\
\hline Total cholesterol & $\mathrm{mg} / \mathrm{ml}$ & $84.20 \pm 1.52$ & $97 \pm 2.79$ & $68 \pm 1.47$ & $81 \pm 3.10$ \\
\hline LDL & $\mathrm{mg} / \mathrm{ml}$ & $8.6 \pm 1.52$ & $10.83 \pm 2.79$ & $8.83 \pm 1.47$ & $9 \pm 3.10$ \\
\hline HDL & $\mathrm{mg} / \mathrm{ml}$ & $48.2 \pm 15.61$ & $54 \pm 3.52$ & $39.17 \pm 2.99$ & $47.5 \pm 5.01$ \\
\hline Triglycerides & $\mathrm{mg} / \mathrm{ml}$ & $107.40 \pm 51.41$ & $84 \pm 11.66$ & $116.83 \pm 26.06$ & $108.33 \pm 8.12$ \\
\hline SBP & $\mathrm{mmHg}$ & $110.20 \pm 1.79$ & $103.33 \pm 9.14$ & $103 \pm 8.72$ & $102.50 \pm 7.45$ \\
\hline Insulin & $\mathrm{ng} / \mathrm{ml}$ & $0.53 \pm 0.13$ & $0.51 \pm 0.04$ & $0.65 \pm 0.15$ & $0.57 \pm 0.07$ \\
\hline Glucose & $\mathrm{nmol} / \mu \mathrm{l}$ & $1.91 \pm 0.49$ & $2.22 \pm 0.10$ & $2.21 \pm 0.13$ & $2.26 \pm 0.04$ \\
\hline Weight & $\mathrm{g}$ & $23.77 \pm 4.38$ & $26.95 \pm 1.48$ & $25.77 \pm 1.30$ & $27.77 \pm 1.92$ \\
\hline $\begin{array}{l}\text { Improved } \\
\text { weight change }(\%)\end{array}$ & & - & 79 & 49 & - \\
\hline
\end{tabular}

MET, metformin; DNM, diabetic nutrient mix; LDL, low-density lipoprotein; HDL, high-density lipoprotein; SBP, systolic blood pressure.

positive increase in the concentration of fructosamine, with the MET arm showing a greater increase in serum concentration compared to the fructose-fed arm (392.67 \pm 40.69 and $365.80 \pm 42.82 \mu \mathrm{mol} / 1$, respectively) and negative control levels of $338.83 \pm 29.01 \mu \mathrm{mol} / 1$. The DNM-fed group showed a significantly lower fructosamine concentration than the fructose-only group (325.50 \pm 21.60 and $365.80 \pm 42.82 \mu \mathrm{mol} / 1$, respectively) $(\mathrm{p}=0.036)$. Of note is the 2 -fold percentage increase in the fructosamine levels of the MET cohort compared to the fructose-only cohort. The DNM cohort exhibited a $3.94 \%$ decrease in fructosamine concentration, whereas the MET cohort increased by $15.89 \%$ compared to the controls (Fig. 2). Serum fructosamine fluctuations between the groups correlated within generalized IDEXX indices for glycemic control in other mammalian species (excellent, 300-350 $\mu \mathrm{M}$; good, 350-400 $\mu \mathrm{M}$; fair, 400-450 $\mu \mathrm{M}$ and poor, $>450 \mu \mathrm{M})$.

Serum lipid profiles. Total cholesterol and lipoprotein concentrations were measured in all of the cohorts. The DNM-fed cohort showed an average decrease in total serum cholesterol compared to the normal diet control $(68 \pm 3.52$ and $81 \pm 5.62 \mathrm{mg} /$ dl, respectively), as shown in Fig. 3. A significant reduction was observed in the DNM-fed cohort compared to the fructose-fed cohort. Analysis of the MET-fed cohort showed an increase in total serum cholesterol $(97 \pm 10.10 \mathrm{mg} / \mathrm{dl})$. Fructose-fed mice showed no difference in total cholesterol when compared to the normal diet controls $(84.2 \pm 1.52$ and $81 \pm 5.62 \mathrm{mg} / \mathrm{dl}$, respectively) ( $\mathrm{p}=0.73)$. High-density lipoprotein (HDL), lowdensity lipoprotein (LDL) and triglyceride levels did not vary significantly.

Physiological parameters: systolic blood pressure and weight. Both the MET-fed and DNM-fed mice showed a decrease in the average systolic blood pressure when compared to the fructose-fed mice $(103.33 \pm 9.14$ and $103 \pm 8.72 \mathrm{vs}$. 110.2 $\pm 1.79 \mathrm{mmHg}$, respectively) (Fig. 4). Fructose feeding

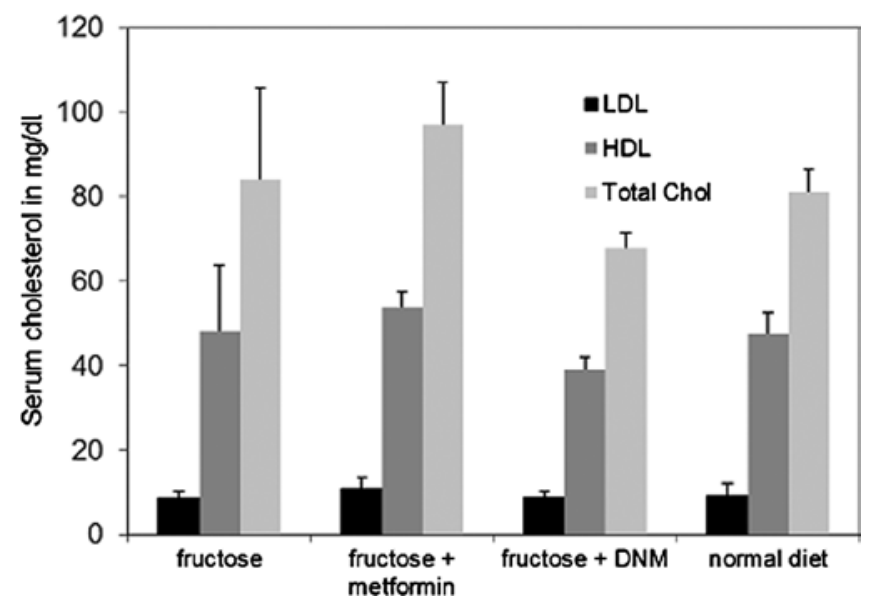

Figure 3. Comparative effects of metformin (MET) and diabetic nutrient mixture (DNM) on lipid profiles of fructose-fed mice. Changes among the high-density lipoprotein (HDL) and low-density lipoprotein (LDL) profiles among and between all of the groups were not significant. At 7 weeks, the DNM group exhibited a decrease in total cholesterol compared to the fructose-fed mice $(\mathrm{p}<0.05)$ while the MET group exhibited an increase in total cholesterol $(\mathrm{p}<0.05)$.

significantly impaired growth weight compared to normal diet controls $(23.77 \pm 4.38$ and $27.77 \pm 1.92 \mathrm{~g}$, respectively) $(\mathrm{p}=0.034)$. Additionally, the DNM and MET cohorts showed a statistically non-significant increase in absolute weight change compared to fructose-fed controls $(25.77 \pm 1.30$ and $26.95 \pm 1.48$ vs. $23.77 \pm 4.38 \mathrm{~g}$, respectively). The percentage improvement in weight gain is expressed as [(fructose group weight - control weight) - (treatment group weight - control weight)]/(fructose group weight-control weight) and pertains to the restoration of growth weight lost by fructose feeding.

Serum insulin and glucose. Insulin concentrations were reduced compared to the normal diet controls, with the MET group exhibiting a greater effect than the fructose-fed group 
Table II. Comparative effects of diets and treatments on urinary glucose, protein and creatinine levels.

\begin{tabular}{|c|c|c|c|c|c|}
\hline $\begin{array}{l}\text { Uninary } \\
\text { analyses }\end{array}$ & Units & $\begin{array}{l}\text { Fructose }(12 \%) \\
\text { and normal diet } \\
\qquad(\mathrm{n}=6)\end{array}$ & $\begin{array}{c}\text { Fructose }(12 \%) \\
\text { and MET }(2 \mathrm{mg} / \mathrm{ml}) \\
\text { and normal diet } \\
(\mathrm{n}=5)\end{array}$ & $\begin{array}{l}\text { Fructose }(12 \%) \\
\text { and DNM } \\
(\mathrm{n}=5)\end{array}$ & Normal diet \\
\hline Glucose & $\mathrm{nmol} / \mu \mathrm{l}$ & $0.63 \pm 0.17$ & $0.37 \pm 0.06$ & $0.69 \pm 0.10$ & $0.49 \pm 0.08$ \\
\hline Protein & $\mathrm{mg} / \mathrm{ml}$ & $31.16 \pm 10.23$ & $22.73 \pm 8.95$ & $42.44 \pm 9.18$ & $25.35 \pm 7.70$ \\
\hline Creatinine & $\mu \mathrm{g} / \mu \mathrm{l}$ & $0.84 \pm 0.28$ & $0.44 \pm 0.12$ & $0.92 \pm 0.21$ & $0.57 \pm 0.18$ \\
\hline
\end{tabular}

MET, metformin; DNM, diabetic nutrient mix.

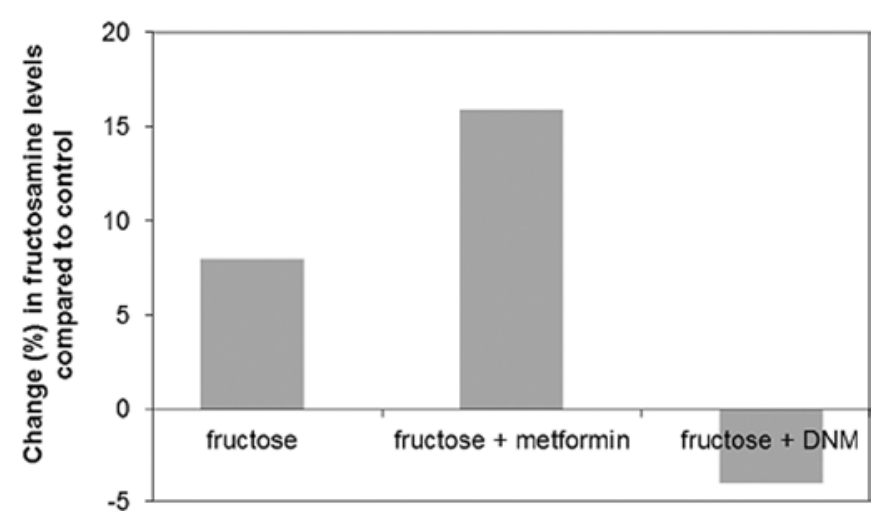

Figure 2. Comparative effects of metformin (MET) and diabetic nutrient mixture (DNM) on fructosamine levels in fructose-fed mice. The DNM group demonstrated significantly lower fructosamine concentration $(3.94 \%$ decrease) than the control (fructose-only fed) group, whereas the MET-treated group showed a $15.9 \%$ increase in fructosamine compared to the control. A t-test performed between the DNM group vs. the fructose alone group and ANOVA for all groups yielded $\mathrm{p}<0.05$.

$(0.51 \pm 0.04$ and $0.53 \pm 0.13 \mathrm{ng} / \mathrm{ml}$, respectively). The DNM group had a restorative effect on the insulin levels compared to the normal diet controls. No significant changes were found in the concentration of insulin or in the levels of serum glucose among the groups.

Urine analyses. Urine analyses were conducted on 22 mice ( $\mathrm{n}=5$ for the two treated groups, $\mathrm{n}=6$ for the remaining groups) for glucose, protein and creatinine (Table II). Urine glucose increased in the DNM mice and decreased in the MET mice $(0.69 \pm 0.10$ and $0.37 \pm 0.06$, respectively). Normalizing the values to urine protein concentrations increased changes towards control conditions (data not shown). Proteinuria was observed in DNM-fed mice, achieving a value of $42.44 \pm 9.18 \mathrm{mg} / \mathrm{ml}$, elevated compared to fructose-fed and normal diet mice $(31.16 \pm 10.23$ and $25.35 \pm 7.70 \mathrm{mg} / \mathrm{dl}$, respectively). MET-fed mice showed a decrease in the concentration of protein at $22.73 \pm 8.95 \mathrm{mg} / \mathrm{ml}$. Urinary creatinine showed an increase in the fructose-fed and DNM groups and a decrease in the MET group compared to the normal diet controls $(0.84 \pm 0.28,0.92 \pm 0.21$ and $0.44 \pm 0.11 \mu \mathrm{g} / \mu 1$, respectively $)$. However, when normalized to total urine protein, the MET and DNM groups decreased the ratios towards control conditions (data not shown).

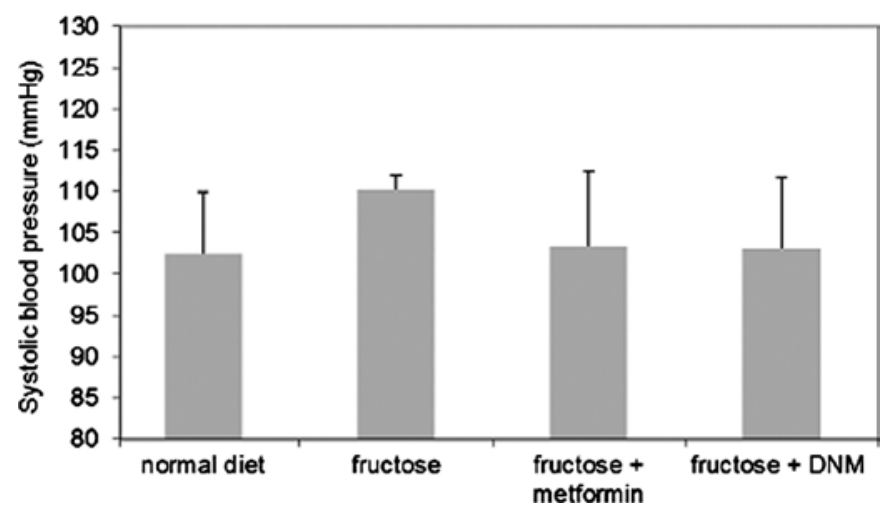

Figure 4. Comparative effects of metformin (MET) and diabetic nutrient mixture (DNM) on systolic blood pressure (SBP) in fructose-fed mice. Fructose-fed mice, compared to the untreated control, had an overall increase in SBP $(\mathrm{p}<0.05)$. When compared to fructose-fed mice, both the MET and DNM groups had a significant decrease in SBP.

\section{Discussion}

Beneficial effects of DNM in fructose-fed mice. DNM showed beneficial effects in lowering systolic blood pressure, serum fructosamine, and total cholesterol in fructose-fed wild-type mice. Insulin levels did not predict improvements in systolic blood pressure or weight, indicating a complex dependency. The improvements of cardiovascular parameters are of particular importance in diabetic patients, since the greatest cause of mortality associated with diabetes continues to be cardiovascular events (27).

In addition to systolic blood pressure benefits, DNM had a restorative effect on weight in DNM fed mice compared to fructose-fed mice. Diabetes mellitus is known to cause weight loss and weight gain, depending on the insulin sensitivity of cells. A loss of insulin sensitivity causes weight loss, while hyperglycemia with intact insulin sensitivity causes obesity. Additionally, obesity may cause adipose tissue as an endocrine organ to release pro-inflammatory factors that lead to diabetes mellitus. Within this study, fructose feeding significantly reduced growth weight in immature mice that MET and DNM helped to restore.

These benefits conferred by DNM reiterate the utility of antioxidants, vitamins, amino acids and polyphenols in diabetes mellitus and/or dietary-induced MS. We showed that the reduction in fructosamine, an early glycation adduct, is significant as it is a crucial marker of glycation-mediated 


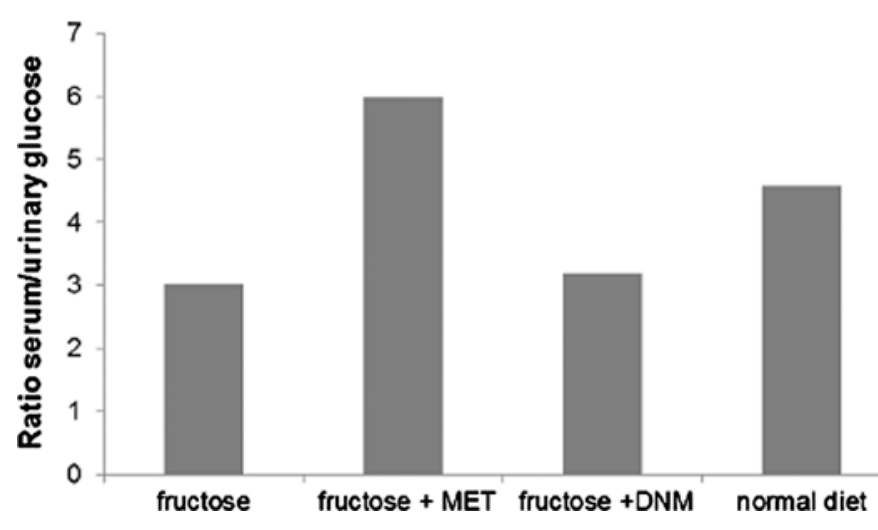

Figure 5. Comparative effects of metformin (MET) and diabetic nutrient mixture (DNM) on ratios between mean serum glucose concentration and urinary glucose concentration in fructose-fed mice. MET increased the ratio of serum glucose concentration to urinary glucose concentration compared to ratios observed in fructose-fed, DNM, and normal groups.

serum protein damage. 'Dicarbonyl-free radicals' are a normal byproduct of metabolism, the formation of which is accelerated in diabetes (28), and is involved in diabetic complications. Thus, the rationale for employing polyphenolics such as procyanidins and reactive carbonyl quenching amino acids, such as arginine and lysine $(29,30)$, was not only to improve individual biochemical markers, but also to prevent damage by excess serum sugar, thereby negating sugar free radicals and sequestering oxidative radicals.

Discordant effects of MET on physiological and serum biochemical parameters. The positive control for the two arms of the study was MET administered in drinking water. In human medicine, MET is effective at lowering blood glucose, while possessing a collection of undesirable side effects associated with varying degrees of risk to patients, including the up-regulation of $\beta$-amyloid (12). At $2 \mathrm{mg} / \mathrm{ml}$, and taking into account the daily drinking habits of mice, this regimen delivered $300-500 \mathrm{mg} / \mathrm{kg} /$ day of MET. In this study, MET elevated fructosamine and total cholesterol in the dietary-induced MS model beyond fructose levels alone.

Guanidines are widely used and are considered to be efficacious in the control of hyperglycemia. In our experiments, mice administered the MET mixture had relatively normal serum glucose levels and experienced a decrease in urinary glucose. However, pharmacological intervention with these agents is not completely innocuous, nor completely modifies the complex pathogenesis of MS and diabetes.

This is not the first report of discordant effects of pharmacotherapy of diabetes, with physiological and biochemical parameters responding independently of each other $(31,32)$. This point should be emphasized in analyzing results that focus on one organ system alone, rather than results from a whole organism. Fructose has a stunting effect in young growing mice, perhaps by competitive shunting of the metabolism towards a catabolic state and/or decreasing insulin sensitivity, which was not measured in this study. This may have significance to dietary factors of human health in childhood and adolescence.

The reduction of urinary creatinine and glucose by MET, as well as proteinuria with a slight reduction in serum glucose, is not an indicator of serum improvement in mice induced to have MS. The decrease in diabetic urinary markers by MET and the increase in serum fructosamine and cholesterol suggest that a lower clearance of excessive blood sugar by the kidneys, without a significant change in blood glucose, allows the sugars to accumulate in other physiological reservoirs. The increase in the ketoamine adduct, fructosamine, appears to reflect the increased ratio of blood glucose concentration to a reduced urinary glucose concentration (Fig. 5). These early glycation adducts contribute to AGE deposition in the target organs of diabetes: the eyes, kidneys, arteries and almost anywhere where free lysine and arginine ligands are found. While kidney function parameters are improved, this may be at the expense of serum biochemical health (31-33). Taken together, these results recommend that prevention of blood protein and tissue protein glycation by excessive sugar and enhancement of renal clearance should be addressed simultaneously. Similarly, the increased renal clearance of toxic adducts and metabolic byproducts may improve blood biochemical parameters at the expense of impending kidney damage. With physiological proteinuria being a normal state in mice (34), these results should be further evaluated to assess whether this inverse correlation between urinary markers and serum health is relevant in human pathogenesis.

In conclusion, these data suggest that nutritional modifications, when administered to adolescent wild-type C57/BL6 $\mathrm{J}$ mice consuming a high fructose diet, confer a benefit in inhibiting the constellation of symptoms present in immature diet-induced MS mice, and that diets high in fructose should be contraindicated for children and adolescents. Specifically, the DNM mixture has beneficial effects in lowering systolic blood pressure and total cholesterol, counteracting the protein damage caused by fructosamine, and raising weight/food consumption in a fructose-fed model independent of blood glucose. Furthermore, divergent biochemical pathways are used to metabolize fructose and glucose that have yet to be clarified. Aberrant modulation of these pathways through excessive fructose consumption may cause biochemical consequences that are as yet unknown and relevant to MS and type 2 diabetes. Further studies with mature mice of wild-type and mutant origin for longer periods of time in relevance to adult onset diabetes are required.

\section{Acknowledgements}

This study was funded by the Dr Rath Health Foundation (Plantation, FL, USA), a non-profit organization.

\section{References}

1. Meigs JB: Epidemiology of type 2 diabetes and cardiovascular disease: translation from population to prevention: the Kelly West award lecture 2009. Diabetes Care 33: 1865-1871, 2010.

2. Cavender MA and Lincoff AM: Therapeutic potential of aleglitazar, a new dual PPAR-alpha/gamma agonist: implications for cardiovascular disease in patients with diabetes mellitus. Am J Cardiovasc Drugs 10: 209-216, 2010.

3. Perez-Pozo SE, Schold J, Nakagawa T, Sánchez-Lozada LG, Johnson RJ and Lillo JL: Excessive fructose intake induces the features of metabolic syndrome in healthy adult men: role of uric acid in the hypertensive response. Int J Obes 34: 454-461, 2010.

4. Farah V, Elased KM, Chen Y, Key MP, Cunha TS, Irigoyen MC and Morris M: Nocturnal hypertension in mice consuming a high fructose diet. Auton Neurosci 130: 41-50, 2006. 
5. Rabbani N and Thornalley PJ: Dicarbonyls linked to damage in the powerhouse: glycation of mitochondrial proteins and oxidative stress. Biochem Soc Trans 36: 1045-1050, 2008.

6. Hofmann SM, Dong HJ, Li Z, Cai W, Altomonte J, Thung SN, Zeng F, Fisher EA and Vlassara H: Improved insulin sensitivity is associated with restricted intake of dietary glycoxidation products in the db/db mouse. Diabetes 51: 2082-2089, 2002.

7. Armbruster D: Fructosamine: structure, analysis, and clinical usefulness. Clin Chem 33: 2135-2163, 1987.

8. Baker J, O'Connor JP, Metcalf PA, Lawson MR and Johnson RN: Clinical usefulness of estimation of serum fructosamine concentration as a screening test for diabetes mellitus. Br Med J (Clin Res Ed) 287: 863-867, 1983.

9. Van Dieren S, Beulens JW, van der Schouw YT, Grobbee DE and Neal B: The global burden of diabetes and its complications: an emerging pandemic. Eur J Cardiovasc Prev Rehabil 17 (Suppl 1): S3-S8, 2010.

10. Zhou G, Myers R, Li Y, Chen Y, Shen X, Fenyk-Melody J, Wu M, Ventre J, Doebber T, Fujii N, et al: Role of AMP-activated protein kinase in mechanism of metformin action. J Clin Invest 108: $1167-1174,2001$

11. Wang X, Liu X, Zhan Y, Lavallie ER, Diblasio-Smith L, Collins-Racie L, Mounts WM, Rutkowski JL, Xu X, Goltsman I, et al: Pharmacogenomic, physiological, and biochemical investigations on safety and efficacy biomarkers associated with the peroxisome proliferator-activated receptor-gamma activator rosiglitazone in rodents: a translational medicine investigation. J Pharmcol Exp Ther 334: 820-829, 2010.

12. Chen Y, Zhou K, Wang R, Liu Y, Kwak YD, Ma T, Thompson RC, Zhao Y, Smith L, Gasparini L, et al: Antidiabetic drug metformin (GlucophageR) increases biogenesis of Alzheimer's amyloid peptides via up-regulating BACE1 transcription. Proc Natl Acad USA 106: 3907-3912, 2009.

13. Piatti PM, Monti LD, Valsecchi G, Magni F, Setola E, Marchesi F, Galli-Kienle M, Pozza G and Alberti KG: Long-term oral L-arginine administration improves peripheral and hepatic insulin sensitivity in type 2 diabetic patients. Diabetes Care 24: $875-880,2001$

14. Sim MK, Wong YC, Xu XG, Sim SZ and Tsi D: Hypoglycemic action of chicken meat extract in type-2 diabetic KKAy mice and GK rats. Biosci Biotechnol Biochem 73: 2583-2588, 2009.

15. González-Ortiz M, Martínez-Abundis E, Robles-Cervantes JA, Ramírez-Ramírez V and Ramos-Zavala MG: Effect of thiamine administration on metabolic profile, cytokines and inflammatory markers in drug-naïve patients with type 2 diabetes. Eur J Nutr 50: 145-149, 2011.

16. Arora S, Lidor A, Abularrage CJ, Weiswasser JM, Nylen E, Kellicut D and Sidawy AN: Thiamine (vitamin B1) improves endothelium-dependent vasodilatation in the presence of hyperglycemia. Ann Vasc Surg 20: 653-658, 2006.

17. Cunningham JJ, Mearkle PL and Brown RG: Vitamin C: an aldose reductase inhibitor that normalizes erythrocyte sorbitol in insulin-dependent diabetes mellitus. J Am Coll Nutr 134: 344-350, 1994

18. Zanoni JN, Pereira RVF and De Freitas P: Effect of the ascorbic acid treatment on the NADHd-positive myenteric neurons of diabetic rats proximal colon. Braz Arch Biol Technol 50: 31-38, 2007.

19. Zygmunt K, Flaubert B, MacNeil J and Tsiani E: Naringenin, a citrus bioflavonoid, increases muscle cell glucose uptake via AMPK. Biochem Biophys Res Commun 398: 178-183, 2010.

20. Urios P, Grigorova-Borsos AM and Sternberg M: Flavonoids inhibit the formation of the cross-linking AGE pentosidine in collagen incubated with glucose, according to their structure. Eur J Nutr 46: 139-146, 2007.
21. Peng X, Cheng KW, Ma J, Chen B, Ho CT, Lo C, Chen F and Wang M: Cinnamon bark proanthocyanidins as reactive carbonyl scavengers to prevent the formation of advanced glycation endproducts. J Agric Food Chem 56: 1907-1911, 2008.

22. Tanaka M, Misawa E, Ito Y, Habara N, Nomaguchi K, Yamada M, Toida T, Hayasawa H, Takase M, Inagaki M, et al: Identification of five phytosterols from Aloe vera gel as anti-diabetic compounds. Biol Pharm Bull 29: 1418-1422, 2006.

23. Suwannaphet W, Meeprom A, Yibchok-Anun S and Adisakwattana S: Preventive effect of grape seed extract against high-fructose diet-induced insulin resistance and oxidative stress in rats. Food Chem Toxicol 48: 1853-1857, 2010.

24. Liu J, Sun H, Duan W, Mu D and Zhang L: Maslinic acid reduces blood glucose in KK-Ay mice. Biol Pharm Bull 30: 2075-2078, 2007.

25. Yi X and Maeda N: Alpha-lipoic acid prevents the increase in atherosclerosis induced by diabetes in apolipoprotein E-deficient mice fed high-fat/low-cholesterol diet. Diabetes 55: 2238-2244, 2006.

26. Oron-Herman M, Kamari Y, Grossman E, Yeger G, Peleg E, Shabtay Z, Shamisss A and Sharabi Y: Metabolic syndrome: comparison of the two commonly used animal models. Am J Hypertens 21: 1018-1022, 2008.

27. Siscovick DS, Sotoodehnia N, Rea TD, Raghunathan TE, Jouven X and Lemaitre RN: Type 2 diabetes mellitus and the risk of sudden cardiac arrest in the community. Rev Endocr Metab Disord 11: 53-59, 2010.

28. Monnier VM, Sell DR, Nagaraj RH, Miyata S, Grandhee S, Odetti P and Ibrahim SA: Maillard reaction-mediated molecular damage to extracellular matrix and other tissue proteins in diabetes, aging, and uremia. Diabetes 41 (Suppl 2): 36-41, 1992.

29. Pedchenko VK, Chetyrkin SV, Chuang P, Ham AJ, Saleem MA, Mathieson PW, Hudson BG and Voziyan PA: Mechanism of perturbation of integrin-mediated cell-matrix interactions by reactive carbonyl compounds and its implication for pathogenesis of diabetic neuropathy. Diabetes 54: 2952-2960, 2005.

30. Lankin VZ, Tikhaze AK, Kapel'ko VI, Shepel'kova GS Shumaev KB, Panasenko OM, Konovalova GG and Belenkov YN: Mechanisms of oxidative modification of low density lipoproteins under conditions of oxidative and carbonyl stress. Biochemistry (Mosc) 72: 1081-1090, 2007.

31. Nyengaard JR, Chang K, Berhorst S, Reiser KM, Williamson JR and Tilton RG: Discordant effects of guanidines on renal structure and function and on regional vascular dysfunction and collagen changes in diabetic rats. Diabetes 46: 94-106, 1997.

32. Degenhardt TP, Fu MX, Voss E, Reiff K, Neidlein R, Strein K, Thorpe SR, Baynes JW and Reiter R: Aminoguanidine inhibits albuminuria, but not the formation of advance glycation end-products in skin collagen of diabetic rats. Diabetes Res Clin Pract 43: 81-89, 1999.

33. Hujberts MS, Wolffenbuttel BH, Crijns FR, Nieuwenhuijzen Kruseman AC, Bemelmans MH and Strujiker Boudier HA: Aminoguanidine reduces regional albumin clearance but not urinary albumin excretion in streptozotocin-diabetic rats. Diabetologia 37: 10-14, 1994

34. Thung PJ: Physiological proteinuria in mice. Acta Physiol Pharmacol Neerl 10: 248-261, 1962. 